\title{
A Framework to Support Collaborative Learning Using Social Media
}

\author{
Josphat Karani ${ }^{1}$, Florence K. Maweu ${ }^{2}$ \\ ${ }^{1,2}$ Department of Computing and IT, Kirinyaga University College, Box 143-Kutus, Kenya
}

\begin{abstract}
New frameworks for developing interactions between the actors of learning processes require new ways of gaining an understanding of such processes. Today, these frameworks are of a technological kind, and their prime expression is found in social networking sites, which have already been called 'social operating systems'. Unfortunately, we are not able to fully utilize this collective knowledge being generated through group member's interaction. The focus of this study, was to ensure that the knowledge being generated through social media is not lost. This was achieved by developing a framework that was able to extract, classify and store the classified comments from a social media account to support collaborative leering. The study focused only on developing an enabling environment for learners to interact and be able to capture and store the knowledge generated through these interaction.
\end{abstract}

Keywords: A Framework to Support Collaborative Learning Using Social Media

\section{Background of the study}

E-learning as we know it has been around for the last decade and it has change from being a radical idea to something that is regarded as mainstream in our education institution especially higher learning institutions. In Most of these institutions, E-learning is in form ofa learning managements system (LMS) which allows tutors to publish course content.

Social networking sites like Twitter is an example of a Web 2.0 social networking site, which has enormous potential in the field of education despite the fact that it was not designed as an environment for constructing and managing learning experiences. These web technologies have come with a new generation of learners the I or $\mathrm{Z}$ generation as described by [1] generation who's technology is part of their DNA, to them technology is not a tool but a part of life they are constantly online creating and sharing an array of content where the learners have no off switch.

Interest in collaboration is a natural outgrowth of the trend in education toward active learning, whereby students become involved in constructing their own knowledge through discovery, discussion, and expert guidance. Collaboration affords students the opportunity to share thoughts and interact with peers, facilitators, and experts in a defined area [2].

For the new generation of learners going to the LMS to find answers to their questions is not an option they prefer using web 2.0 tools like Google, Wikipedia or YouTube, or simply posting questions to their networks on Twitter or Facebook in order to get immediate, up-to-date and relevant answers.

The educational potential of social media is extraordinary, and particularly so if a fresh look is taken at the concepts of education and training, and emphasis is placed on the social nature of knowledge construction that is collaborative learning.

\subsection{Problem Statement}

New frameworks for developing interactions between the actors of learning processes require new ways of gaining an understanding of such processes. Today, these frameworks are of a technological kind, and their prime expression is found in social networking sites, which have already been called 'social operating systems' [2].

The use of these social networking sites is increasing in all areas of society but, although students have been active in social networking for almost a decade now, during this time, schools and teachers have largely ignored them. It is common knowledge that when students need to make sense of some information or just needs a quick answer, they turn first to their peers. Hence social media networks like Twitter are providing a platform for this kind of interaction. Through these interactions a lot of collective knowledge being created and shared in this social media sites like Twitter.

\section{The gap}

Unfortunately, we are not able to fully utilize this collective knowledge being generated through group member's interaction due to the inherent limitations of social media networking sites. The focus of this study is that social media accounts lack a true system for tagging, filtering, searching and organizing information. The speed, at which posts are produced, is the same speed at which it disappears into older posts, they lack a way of 'storing knowledge', whereby knowledge generated can be classified, saved, and easily and quickly retrieved. Trying to locate a message that we know is somewhere within a Twitter account can often be very chaotic. These limitations of social media as a tool for supporting collaborative learning are what this research addresses.

\subsection{Goal of the project}

Develop a technique for harvesting, classifying and storing comments from a social media account to support collaborative learning. 


\section{International Journal of Science and Research (IJSR) \\ ISSN (Online): 2319-7064}

Index Copernicus Value (2013): 6.14 | Impact Factor (2015): 6.391

\subsection{Objectives}

a) Develop a way for capturing data from a social media discussion forum.

b) Develop a text classifier that is able to classify the data from social media into groups based on various categories.

c) Develop a platform that is able to store the classified data (from b above) for easy and quick retrieval.

\section{Literature Review}

\subsection{Learning Communities}

Learning communities are receiving considerable attention by higher education scholars and practitioners it worth noting the concept is not new.

The concept of learning communities has been discussed for more than two decades [3]. Research has clearly shown that functioning in a community can enhance the learning that occurs among community members [4].

While Web 2.0 tools like twitter have been in existence for many years they seem to have little or no impact on the structure and conception of the old learning paradigms on which today's curricula are built Bartolomé, Antonio [5] argues.

\subsection{Educational potential that Twitter offers for collaborative learning}

Imagine a 20 minute lecture where all your students back channel about what you're saying. Outside guests or experts are invited in. Someone acts as a "rudder" to keep the conversation on track. The discussion is displayed on a SMARTboard or with a projector. The chatcast is immediately dumped into a wiki. The rest of the class is devoted to reorganizing the wiki clarifying what was said, answering questions (student to student as well as teacher to student; and don't forget the people, students, teachers, mentors or parents beyond the glass walls of the room) summarizing the big ideas, reframing the discussion in terms of what needs to be explained again and where we're going next. Imagine the possibilities [6]

As Terry Friedmanputs it in the above paragraph the possibilities are endless when it comes to the educational potential of social media.

\subsection{Traditional LMS - Elimika program}

Most Learning Managements System (LMS) out there simply automate the model of a normal classroom. The only difference being that the learners do not have to meet in the same place at the same time. Most of these systems are missing a vital ingredient that is other people. The advent of social media tools has provided us with a way of overcoming this deficiency, although not fully exploited social media has a lot of potential for teaching and learning. It is a tool that allows one to connect with likeminded people with whom they can communicate, share ideas, resources as well as experiences. Hence the reason that we are moving towards integrating LMS with web 2.0 tools. A good example of this is Elimka. Elimika is a Learning Management System (LMS) developed at the Kenya Institute of curriculum development (KICD) [7].

\subsection{Limitations of social media and LMS}

From the above discussion on LMS and Web 2.0 (Elimika) and social media (Twitter), it is clear that these web 2.0 enabled platforms are technologically rich, adaptable expandable and capable of supporting collaborative-working experiences in learning communities. However, it is also evident [2] that these platforms have some limitations in the implementation of learning experiences, either because some of the native tools are not well-developed, or because certain tools are quite simply missing. Some of these limitations include:

Both (LMS 2.0 and social media) lack a true system for tagging, filtering, searching and organizing information. The speed at which news is produced, is the same speed at which it disappears into older posts. They do not allow for knowledge generated to be classified, saved, and easily and quickly retrieved.

The drop-down comments system on walls tends to make it hard to see information. If a user is not a habitual user, the presence of new comments may be overlooked. Likewise, the difference between 'read' and 'unread' items is not easy to see, and is occasionally too spurious. Trying to locate a message that we know is somewhere can often be very chaotic.

\section{Conceptual Framework}

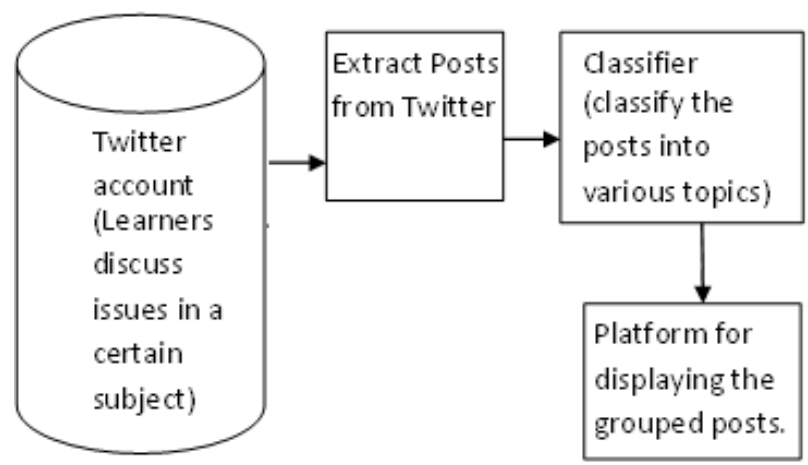

Figure 1: Proposed solution overview

\subsection{Prototype Development Methodology}

The system development methodology used was Agile development methodology. Agile development methodology was found to be a good option to implement the proposed solution in an incremental approach through an iterative approach. The methodology basically resulted to inspection and adoption approach which greatly reduces both the development cost and time. For each iteration there was an output, a component of the proposed solution that was evaluated against the requirements. 


\section{International Journal of Science and Research (IJSR) \\ ISSN (Online): 2319-7064}

Index Copernicus Value (2013): 6.14 | Impact Factor (2015): 6.391

\subsection{High level view of the classifier development process}

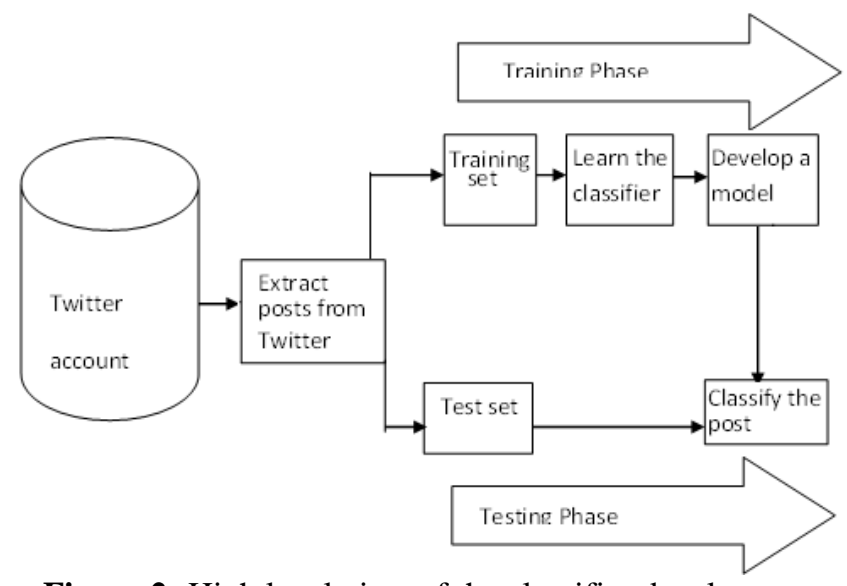

Figure 2: High level view of the classifier development process

\section{Prototype Development and Implementation}

\subsection{The system design Process}

The prototype development methodology used the iterative feature driven development (FDD) a variant of the agile software development methodology. The design process involved first the development of an overall model for the prototype (refer to Fig 1).The feature development methodology requires that a feature list be developed after the overall model is created hence the next step was identifying a set of features that are required in order to achieve the set objectives of this study. The overall model was broken down to several features based on the three objectives of the study as illustrated below:

\begin{tabular}{|c|c|c|}
\hline NO & Objective & $\begin{array}{c}\text { The Feature that was } \\
\text { developed }\end{array}$ \\
\hline $\mathbf{1}$ & $\begin{array}{c}\text { Develop a way for capturing } \\
\text { data from a social media } \\
\text { discussion forum. }\end{array}$ & $\begin{array}{c}\text { Twitter extractor (extract } \\
\text { comments from a twitter } \\
\text { account) }\end{array}$ \\
\hline $\mathbf{2}$ & $\begin{array}{c}\text { Develop a text classifier that is } \\
\text { able to classify the data from } \\
\text { social media into groups based } \\
\text { various categories. }\end{array}$ & $\begin{array}{c}\text { A text cleaner } \\
\text { A Naïve Bayes classifier }\end{array}$ \\
\hline $\mathbf{3}$ & $\begin{array}{c}\text { Develop a platform that is able } \\
\text { to store the classified data for } \\
\text { easy and quick retrieval. }\end{array}$ & $\begin{array}{c}\text { A Mysql database to store } \\
\text { the extracted and } \\
\text { classified tweets } \\
\text { A platform for supporting } \\
\text { easy and quick retrieval } \\
\text { of the classified tweets }\end{array}$ \\
\hline
\end{tabular}

\section{Evaluation Results and Achievements}

The purpose of this study was to examine how Web 2.0 tools like social media (twitter) can be used to support the practice of meaning making among learners i.e. collaborative learning. The system was tested against the set overall goal of the study which was to develop a technique that will be able to extract posts from a social media account classifier and store them to support collaborative learning.

Data on actual learner participation in online discussion was collected over a period of two weeks. A satisfaction survey was then conducted at the end of the evaluation period through a questionnaire.

The questionnaire had three sections. The first section looked at whether the learners had social media accounts and if they used these accounts for learning purposes. This section of the questionnaire was given to the participants before they started interacting with the prototype. The second section related to usability of the prototype; these were set to evaluate how easy it was to use the prototype with minimal or no training. The third section considered the functionality of the prototype as spelled out by the research objectives that is, was the system able to support collaborative learning through the developed prototype.

\subsection{Initial Study}

The first part of the questionnaire required participants to provide background data on whether they had social media accounts, and if they did whether they used them for educational purposes. All fifteen participants had social media accounts, and twelve of them were frequent users; they visited their accounts at least once a day.

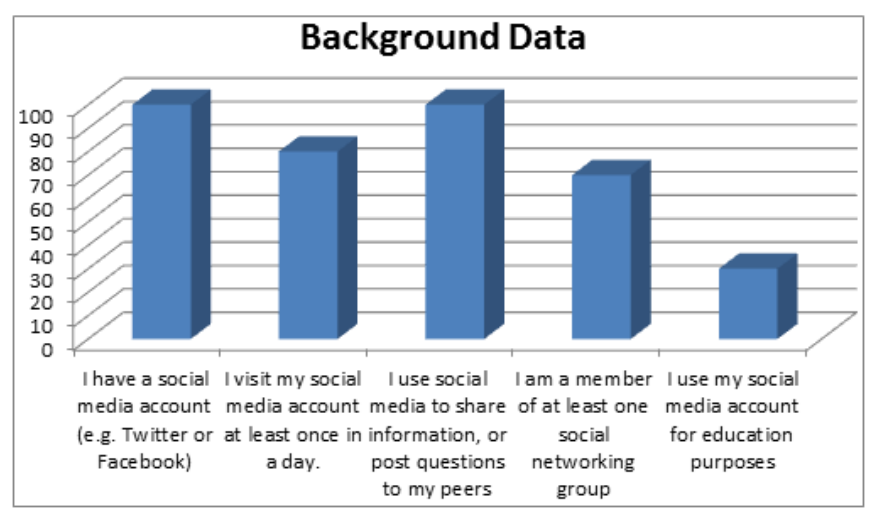

Figure 3: Background data on learners use of social media

\subsection{Evaluation of the prototype on Usability}

The majority of the participants evaluated indicated that the system was easy to use. $80 \%$ which is twelve learners strongly agreed that the prototype was easy to navigate and that all the important links were visible, since it was similar to social media accounts which they have been using. Thirteen learners, that is $86 \%$, strongly agreed that the comments on the prototype were better organized than on Twitter, since they modules comments were grouped separately hence they were easily accessible. Twelve leaner's indicated that they would recommend others to use the prototype.

\subsection{Evaluation of the prototype on Functionality.}

To determine if the prototype achieved the set overall goal of the research, the questionnaire contained a set of question on the functionality of the prototype, i.e. did it support the process of meaning making in a joint activity such as collaborative learning. On this $80 \%$, which is twelve learners strongly agreed that the prototype facilitated exchange of information with others and that they were comfortable interacting with their peers. Thirteen learners, which is $86 \%$ strongly agreed that they felt motivated to 


\section{International Journal of Science and Research (IJSR) \\ ISSN (Online): 2319-7064 \\ Index Copernicus Value (2013): 6.14 | Impact Factor (2015): 6.391}

explore content related to the comments posted by others and that the online discussion enabled them to appreciate different view raised by their peers. Nine learners which is $60 \%$ of the participants strongly agreed that online interaction were valuable and $80 \%$ that is twelve learners also strongly agreed that they learnt more within a shorter period of time than they would have on their own. 86\% which is thirteen learners acknowledged that going through the classified comments on the prototype helped them learn a lot. Twelve learners indicated that they would continue using the prototype.

\section{Conclusion and Recommendations}

\subsection{Conclusion}

The purpose of the study was to develop a framework to support collaborative learning using social media. The research started by pointing out that social media is part of emerging technologies known as Web 2.0. It has enormous potential in the area of teaching and learning.

The study also showed that this potential is not being utilized currently and that the learning institutions that are using these technologies they not able to utilize them fully.It was also pointed out that although Web 2.0 platforms are technologically rich, adaptable and capable of supporting collaborative learning, they have some limitations in the implementation of learning experiences. These limitations of social media as a tool for supporting collaborative learning were the focus of this study.

The researcher developed a prototype that provides an enabling environment for online collaborative learning. The prototype was aimed at addressing the limitations of social media as a tool for supporting collaborative learning, hence taking full advantage of the potential that Web 2.0 has within the field of teaching and learning. The prototype was able to extract tweets from a social media account and then pass them to a classifier. The classifier grouped the tweets into different categories based on various modules that the learners were taking. Finally the prototype was able to store the tweets in a database, which was linked to a web based platform for the learners to interact with.

The prototype was able to address the limitations that social media has as tool for supporting collaborative learning; these included issues of storing the large amounts of knowledge being generated by learners through these sites and providing a way of categorizing comments generated with a social media account.

\subsection{Suggestions for further research}

This study limited itself to the classification of English statements (tweets) only. Therefore there is need to explore how the classifier can be modified to be able to extract and classify statements tweets in other languages like Kiswahili.
[2] Francesc Llorens Cerdà and Neus Capdeferro Planasneus (2011) Facebook's Potential for Collaborative eLearning.

[3] Caverly, D.C., \& MacDonald, L. (2002).Online learning communities. Journal of Developmental Education, 25 (3), 36-37.

[4] Hargis, J. (2005). Collaboration, community and projectbased learning--does it still work online? International Journal of Instructional Media, 32, (2), 157- 162.

[5] Bartolomé, Antonio (2008). Web 2.0 and New Learning Paradigms. eLearning Papers $\mathrm{N}^{\circ}$ 8. ISSN: 1887-1542 www.elearningpapers.eu

[6] Terry Friedman,2007,Twittering in the classroom.

[7] www.elimika.ac.ke

\section{References}

[1] Jayson s. (2006)I Generation has no Off switch 